\title{
ESTUDO NEUROLÓGICO E DO LfQUIDO CEFALORRAQUEANO EM PACIENTES COM A FORMA CRÔNICA DA MOLESTIA DE CHAGAS
}

\author{
EDYMAR JARDIM * \\ J. ARmbrust-Figueiredo **
}

O diagnóstico das formas nervosas crônicas da moléstia de Chagas continua a ser um problema aberto porque o comprometimento do sistema nervoso, muitas vezes exuberante nas formas agudas da doença, não tem, nas formas crônicas, o mesmo substrato anatomopatológico e, conseqüentemente, apresentação neurológica bem definida. Estas formas neurológicas crônicas, citadas como entidades bem caracterizadas por alguns, contestadas e mesmo negadas por outros, merecem estudos mais numerosos e acurados. Na intenção de tentar correlacionar o aspecto sorológico do sangue, com os eventuais achados da semiologia clínica e do exame do liquido cefalorraqueano (LCR) é que empreendemos o presente estudo.

M A T E R I A L

Foram estudados, do ponto de vista neurológico e liquórico, 82 pacientes internados em frenocômio, não sendo considerada a patologia psiquiátrica apresentada por eles. Desse grupo, 27 pacientes eram chagásicos crônicos com positividade da reação de Machado-Guerreiro no sangue; nos 55 restantes esse exame resultou negativo. Todos os pacientes eram do sexo feminino e as suas idades variaram entre 19 e 67 anos.

Foi possivel repetir o exame do líquido cefalorraqueano em 23 dos 27 pacientes inicialmente examinados, após um intervalo de 3 anos. A colheita do sangue e do LCR foi sempre feita em jejum.

Do ponto de vista neurológico, no grupo dos 27 pacientes em que a reação de Machado-Guerreiro se mostrou positiva no sangue, foram encontradas as seguintes alteraçoes: hiperreflexia profunda global (2 casos); hiperreflexia profunda global e sinal de Babinski (1 caso); hipopalestesia dos membros inferiores (1 caso); descoramento papilar bilateral ( 1 caso); estrabismo divergente unilateral (1 caso); microcefalia ( 1 caso) e assimetria facial (1 caso).

No grupo dos 55 pacientes com reação de Machado-Guerreiro negativa, as alteraçôes neurológicas registradas foram as seguintes: hiperreflexia profunda global (1 caso); hiperreflexia profunda global e sinal de Babinski (1 caso); hiporreflexia profunda generalizada ( 2 casos); arreflexia profunda global (1 caso); apalestesia dos membros inferiores (1 caso); rigidez pupilar bilateral (2 casos); discoria (1 caso); estrabismo divergente unilateral ( 2 casos); miose bilateral ( 1 caso) e paresia facial central ( 1 caso).

Trabalho do Departamento de Neuropsiquiatria e Psicologia Médica da Faculdade de Medicina de Ribeirão Preto: * Livre-Docente; ** Professor Titular. 


\section{R E S U L T A D O S}

Os resultados estão consignados nos quadros $1,2,3$ e 4 .

\begin{tabular}{|c|c|c|c|c|c|}
\hline Caso & Reg. & Titulo & Caso & Reg. & Titulo \\
\hline 1 & 1808 & maior que 3,0 & 15 & 1615 & maior que 2,3 \\
\hline 2 & 2867 & maior que 2,6 & 16 & 202-A & maior que 3,0 \\
\hline 3 & 1511 & maior que 2,8 & 17 & 3524 & maior que 2,6 \\
\hline 4 & 0565 & maior que 3,0 & 18 & 2813 & maior que 3,0 \\
\hline 5 & 2373 & maior que 2,6 & 19 & 3903 & maior que 3,0 \\
\hline 6 & 2850 & maior que 3,0 & 20 & 4292 & maior que 2,3 \\
\hline 7 & 1826 & maior que $\mathbf{2 , 6}$ & 21 & 3354 & maior que 1,9 \\
\hline 8 & 1729 & maior que 2,6 & 22 & 2688 & maior que 2,6 \\
\hline 9 & $137-\mathrm{A}$ & maior que 3,0 & 23 & 1391 & maior que 2,6 \\
\hline 10 & 2443 & maior que 2,3 & 24 & 1353 & maior que 3,0 \\
\hline 11 & 3643 & maior que 3,0 & 25 & $0,79-A$ & maior que 3,0 \\
\hline 12 & 1421 & maior que 3,0 & 26 & 2317 & maior que 3,0 \\
\hline 14 & 2315 & maior que 2,6 & 27 & 3218 & maior que 3,0 \\
\hline
\end{tabular}

Quadro 1 - Resultados da reação de Machado-Guerreiro no sangue (técnica de Wadsworth-Maltaner-Maltaner) em 27 pacientes chagásicos.

\begin{tabular}{|c|c|c|c|c|c|c|c|}
\hline Caso & $\begin{array}{l}\text { Citol. } \\
\mathrm{mm}^{3}\end{array}$ & $\begin{array}{l}\text { Proteinas } \\
\text { mg\% }\end{array}$ & $\begin{array}{l}\text { Glicose } \\
\mathrm{mg} \%\end{array}$ & Caso & $\begin{array}{l}\text { Citol. } \\
\mathrm{mm}^{3}\end{array}$ & $\begin{array}{l}\text { Proteinas } \\
\text { mg\% }\end{array}$ & $\begin{array}{l}\text { Glicose } \\
\mathrm{mg} \%\end{array}$ \\
\hline 1 & 1,3 & 28 & 60 & 15 & 3,0 & 23 & 72 \\
\hline 2 & 0,3 & 32 & 68 & 16 & 0,0 & 27 & 64 \\
\hline 3 & 0,3 & 17 & 98 & 17 & 2,0 & 25 & 72 \\
\hline 4 & 1,6 & 20 & 80 & 18 & 1,3 & 29 & 55 \\
\hline 5 & 13,0 & 22 & 74 & 19 & 1,3 & 36 & 90 \\
\hline 6 & 2,0 & 27 & 70 & 20 & 0,0 & 17 & 71 \\
\hline 7 & 0,6 & 29 & 84 & 21 & 0,6 & 14 & 63 \\
\hline 8 & 3,0 & 25 & 56 & 22 & 1,0 & 19 & 70 \\
\hline 9 & 3,0 & 33 & 92 & 23 & 2,0 & 22 & 75 \\
\hline 10 & 4,6 & 19 & 70 & 24 & 1,3 & 27 & 56 \\
\hline 11 & 0,0 & 23 & 65 & 25 & 2,3 & 38 & 80 \\
\hline 12 & 2,0 & 23 & 83 & 26 & 1,0 & 18 & 65 \\
\hline 13 & 0,0 & 25 & 64 & 27 & 1,3 & 22 & 68 \\
\hline 14 & 1,3 & 14 & 65 & & & & \\
\hline
\end{tabular}

Quadro 2 - Resultados do primeiro exame de lfquido cefalorraqueano, colhido por via lombar, nos 27 pacientes chagásicos; em todos os casos as reacões de Wasserman, para cisticercos e de Machado-Guerreiro resultaram negalivas. 


\begin{tabular}{|c|c|c|c|c|c|c|c|}
\hline Caso & $\begin{array}{l}\text { Citol. } \\
\mathrm{mm}^{3}\end{array}$ & $\begin{array}{l}\text { Proteinas } \\
\text { mg\% }\end{array}$ & $\begin{array}{l}\text { Glicose } \\
\text { mg\% }\end{array}$ & Caso & $\begin{array}{l}\text { Citol. } \\
\mathrm{mm}^{3}\end{array}$ & $\begin{array}{c}\text { Proteinas } \\
\text { mg\% }\end{array}$ & $\begin{array}{l}\text { Glicose } \\
\text { mg \% }\end{array}$ \\
\hline 1 & 0,3 & 15 & 56 & 13 & 0,3 & 52 & 48 \\
\hline 2 & 0,0 & 20 & 57 & 14 & 0,0 & 17 & 50 \\
\hline 3 & 0,3 & 17 & 59 & 15 & 1,6 & 19 & 44 \\
\hline 4 & 0,3 & 11 & 55 & 16 & 0,0 & 22 & 49 \\
\hline 5 & 4,0 & 11 & 52 & 17 & 1,0 & 9 & 23 \\
\hline 6 & 0,0 & 16 & 56 & 18 & 0,0 & 19 & 47 \\
\hline 7 & 0,3 & 85 & 54 & 19 & 1,3 & 14 & 52 \\
\hline 8 & 0,3 & 15 & 54 & 24 & 0,6 & 17 & 53 \\
\hline 9 & 0,3 & 23 & 57 & 25 & 0,0 & 18 & 44 \\
\hline 10 & 0,0 & 12 & 50 & 26 & 2,0 & 16 & 57 \\
\hline 11 & 0,0 & 23 & 45 & 27 & 0,0 & 12 & 52 \\
\hline 12 & 0,6 & 19 & 53 & & & & \\
\hline
\end{tabular}

Quadro $s$ - Resultados do segundo exame de líquido cefalorraqueano, feito 3 anos depois do primeiro em 23 dos 27 pacientes chagásicos; em todos eles as reações de Wasserman, para cisticercos e de Machado-Guerreiro resultaram negativas. Apenas em dois casos ( 7 e 13) a pesquisa de globulinas resultou levemente positiva. Material colhido por via suboccipital.

\begin{tabular}{|c|c|c|c|c|c|c|c|c|c|}
\hline Caso & Reg. & $\begin{array}{l}\text { Citol. } \\
\mathrm{mm}^{3}\end{array}$ & $\begin{array}{c}\text { Protei- } \\
\text { nas } \\
\text { mg\% }\end{array}$ & $\begin{array}{l}\text { Glicose } \\
\text { mg\% }\end{array}$ & Caso & Reg. & $\begin{array}{l}\text { Citol. } \\
\mathrm{mm}^{3}\end{array}$ & $\begin{array}{l}\text { Protei- } \\
\text { nas } \\
\text { mg\% }\end{array}$ & $\begin{array}{c}\text { Glicose } \\
\text { mg\% }\end{array}$ \\
\hline 1 & 4110 & 1,6 & 19 & 73 & 29 & 3911 & 1,0 & 23 & 74 \\
\hline 2 & 2621 & 0,6 & 22 & 73 & 30 & 1267 & 0,6 & 13 & 66 \\
\hline 3 & 2295 & 1,0 & 17 & 78 & 31 & 1137 & 1,0 & 22 & 51 \\
\hline 4 & $25 \cap-A$ & 0,3 & 23 & 79 & 32 & 1539 & 3,0 & 23 & 88 \\
\hline 5 & 136-A & ๑), 6 & 24 & 92 & 33 & 185-A & 2,3 & 22 & 100 \\
\hline 6 & 903 & 0,0 & 29 & 70 & 34 & 2380 & 1,0 & 28 & 92 \\
\hline 7 & 3498 & 1,0 & 26 & 75 & 35 & 4099 & 2,0 & 25 & 59 \\
\hline 8 & 3460 & 2,0 & 65 & 92 & 36 & 3991 & 3,0 & 42 & 80 \\
\hline 9 & 2301 & 0,6 & 21 & 77 & 37 & 1211 & 1,0 & 14 & 67 \\
\hline 10 & 1756 & 2,5 & 23 & 57 & 38 & 3819 & 2,0 & 20 & 75 \\
\hline 11 & 2953 & 2,0 & 35 & 70 & 39 & 3983 & 0,3 & 25 & 73 \\
\hline 12 & 0,70-A & 0,6 & 21 & 64 & 40 & 3013 & 0,0 & 14 & 65 \\
\hline 13 & 4122 & 1,0 & 24 & 63 & 41 & 3423 & 1,0 & 19 & 72 \\
\hline 14 & 2958 & 0,6 & 23 & 74 & 42 & 2176 & 0,6 & 38 & 72 \\
\hline 15 & 3381 & 0,6 & 29 & 78 & 43 & $0,17-A$ & 0,0 & 25 & 75 \\
\hline 16 & 2620 & 2,0 & 33 & 98 & 44 & 4084 & 0,3 & 25 & 74 \\
\hline 17 & 2776 & 3,0 & 21 & 68 & 45 & 0,99-A & 0,0 & 25 & 64 \\
\hline 18 & 3439 & 0,6 & 23 & 73 & 46 & 3412 & 2,0 & 19 & 80 \\
\hline 19 & 1548 & 1,0 & 23 & 62 & 47 & 3519 & 3,0 & 30 & 72 \\
\hline 20 & 1642 & 13,8 & 45 & 66 & 48 & 3297 & 0,0 & 39 & 50 \\
\hline 21 & 3235 & 0,3 & 24 & 63 & 49 & 3484 & 0,3 & 20 & 60 \\
\hline 22 & 3305 & 1,0 & 25 & 55 & 50 & 1007 & 0,0 & 29 & 87 \\
\hline 23 & 1760 & 2,0 & 24 & 67 & 51 & 3053 & 0,0 & 13 & 78 \\
\hline 24 & 4127 & 0,6 & 29 & 62 & 52 & 1612 & 0,3 & 21 & 75 \\
\hline 25 & 3341 & 0,0 & 28 & 60 & 53 & 168-A & 0,0 & 18 & 89 \\
\hline 26 & 2806 & 0,3 & 27 & 62 & 54 & 2644 & 0,3 & 23 & 63 \\
\hline 27 & 3743 & 1,0 & 20 & 66 & 55 & 4299 & 2,3 & 23 & 51 \\
\hline 28 & 2984 & 1,6 & 23 & 62 & & & & & \\
\hline
\end{tabular}

Quadro 4 - Resultados do exame do liquido cefalorraqueano em 55 pacientes nã's chagásicos; as reações de Wasserman e de Machado-Guerreiro foram negativas em todos os casos; apenas o de n.o 20 teve positividade da reação para cisticercos, $e$ o caso n.० 8 pesquisa de globulinas levemente positiva. Material colhido por via lombar. 
A análise do liquido cefalorraqueano dos pacientes chagásicos mostrou no primeiro exame as seguintes alterações: hipercitose ( 2 casos) e hiperglicorraquia (5 casos). No segundo exame realizado após 3 anos, encontramos: hipercitose (1 caso); hiperproteinorraquia ( 1 caso); hipoglicorraquia (6 casos) e positividade das reaçōes para globulinas ( 2 casos).

No grupo dos pacientes não chagásicos, as alterações verificadas foram: hipercitose ( 1 caso); hiperproteinorraquia ( 2 casos); hiperglicorraquia ( 7 casos); positividade das reaçōes para globulinas ( 1 caso) e positividade da reação para cisticercos (1 caso).

Chagásicos com alterações neurológicas

$5(18,5 \%)$

Não chagásicos com alteraçōes neurológicas

$7(12,7 \%)$

Chagásicos com alterações liquóricas (1.0 exame)

$7(25,9 \%)$

Chagásicos com alterações liquóricas (2.0 exame)

$8(29,6 \%)$

Não chagásicos com alteracões liquóricas

\begin{abstract}
Quadro 5 - Percentagens das alteracões encontradas nos exames neurológicos e nos exames de liquido cefalorraqueano em 82 pacientes, sendo 27 dhagásicos crônicos (reação de Machado-Guerreiro positiva no sangue) $e$ 55 não chagásicos.
\end{abstract}

\title{
C O M E N T A R I O S
}

No que se refere aos exames laboratoriais ligados à moléstia de Chagas em sua forma crônica, os resultados são controversos. Chagas ${ }^{2}$ descrevendo as formas nervosas crônicas da doença, constatou a presença de parasitas no LCR de alguns pacientes, com sinais evidentes de comprometimento do sistema nervoso central. Villela e Bicalho ${ }^{6}$ assinalaram a positividade da reação de Machado-Guerreiro no LCR de pacientes com a forma crônica da moléstia. Dalma ${ }^{3}$ refere a positividade da reação de fixação de complemento (método de Davies-Romaña-Gil) no LCR de 4 chagásicos de um grupo de 12, sendo o restante do exame normal. A pesqusa sistemática em grande escala feita por Pedreira de Freitas e Mendes ${ }^{5}$ no LCR de pacientes chagásicos crônicos internados em frenocômio não mostrou resultados positivos. A resultados semelhantes chegaram Basso e Basso ${ }^{1}$ e Käfer e col. ${ }^{4}$. Resumindo, encontramos nesses relatos apenas referências a alterações isoladas de hipercitose, hiperproteinorraquia, positividade das reações para pesquisa de globulinas e, eventualmente, positividade na reação de MachadoGuerreiro.

Nossos resultados permitem as seguintes conclusões: 1) não encontramos positividade da reação de Machado-Guerreiro no LCR dos 27 pacientes chagásicos examinados; 2) as alterações liquóricas (hipercitose, hiperproteinorraquia, hipoglicorraquia, hiperglicorraquia, positividade das reações para globulinas) encontradas foram mais freqüentes no grupo chagásico que no grupo não chagásico, em dois exames repetidos com intervalo de três 
anos; 3) as alterações neurológicas foram mais freqüentes no grupo chagásico que no grupo controle; 4) as alteraçōes liquóricas e neurológicas encontradas rão apresentavam características que permitissem diagnosticar qualquer entidade neurológica de caráter orgânico.

\section{R E S U M O}

Exames neurológicos e do líquido cefalorraqueano foram realizados em 82 pacientes, sendo que 27 eram chagásicos crônicos (com reação de MachadoGuerreiro positiva no sangue) e 55 não chagásicos. As alterações neurológicas e do LCR, foram mais freqüentes no grupo de pacientes chagásicos.

\section{$S$ U M M A R Y}

Clinical, cerebrospinal fluid and blocd tests studies in Chagas' disease.

Clinical and cerebrospinal fluid studies were ferformed in 27 patients with chronic Chagas' disease in which the Machado-Guerreiro reaction in the blood serum was positive. The clinical and laboratorial changes were found more frequently in patients with Chagas' disease than in patients of control group.

\section{R E F E R E C I A S}

1. BASSO, G. \& BASSO, R. - Estudios de enfermos del Asilo de Mendigos de Mendoza con reacion de Machado positiva. An. IX \& Reunion Soc. Argent. Pat. Reg. Mendoza, 1936.

2. CHAGAS, C. - Les formes nerveuses d'une nouvelle trypanosomiase (T. cruzi) inoculé par Triatoma megista. Nouv. Iconogr. Salpetrière 26:1-9, 1913.

3. DALMA, J. - Nota sobre el liquido cefalorraquideo en la enfermedad de Chagas. An. Insi. Med. Reg. (Corrientes, Argentina) 4:47-55, 1964.

4. KAfER, J. P.; POCH, G. F.; MONTEVERDE, D. A.; BLANCO, E. D. \& TARSIA, R. - Las manifestaciones neurolojicas en la forma crônica de la enfermedad de Chagas. Rev. Neurol. Buenos Aires 9:199, 1961.

5. PEDREIRA DE FREITAS, J. L \& MENDES, R. T. - Investigaçces sorológicas na forma nervosa crônica da moléstia de Chagas entre pacientes internados em hospital psiquiátrico. Rev. paul. Med. 45:123, 1955.

6. VILLELA, E. \& BICALHO, C. - As pesquisas de laboratório no diagnóstico da moléstia de Chagas. Mem. Inst. Oswaldo Cruz (Rio de Janeiro) 16:13, 1923.

Departamento de Neuropsiquiatria e Psicologia Médica - Faculdade de Medicina - Caixa Postal 301 - 14100 Ribeirão Preto, SP - Brasil. 